\title{
Pelatihan Desain Kemasan Produk UMKM di Tangerang Selatan
}

\section{Annuridya Rosyidta Pratiwi Octasylva ${ }^{1)}$, Shinta Leonita ${ }^{2)}$, Syahril Makosim ${ }^{3)}$}

\author{
${ }^{1}$ Program Studi Manajemen Institut Teknologi Indonesia \\ 2, 3 Program Studi Teknologi Industri Pertanian Institut Teknologi Indonesia \\ e-mail: annuridya@yahoo.com
}

\begin{abstract}
Abstrak
Kemasan (packaging) suatu produk dapat meningkatkan nilai jual dari suatu produk dan jasa, karena menyangkut estetika, ketahanan dan keamanan sekaligus merupakan nilai jual dan citra produk. Nilai jual ini meningkat ketika produk yang dihasilkan mendapat nilai tambah dari kemasan yang menarik. Sedangkan citra produk terkait dengan gambaran produk dalam benak konsumen akan semakin baik apabila produk itu dikemas secara baik, dengan kata lain produk dapat memberi kesan baik bagi konsumen. Pelatihan desain kemasan produk untuk pelaku UMKM di Kota Tangerang Selatan ini untuk memberikan wawasan desain dan bentuk kemasan baru yang membuat produk menjadi lebih bernilai dan aman. Metode yang diterapkan dalam kegiatan ini adalah metode presentasi mengenai pengenalan bentuk dan desain packaging, Metode demonstrasi mengenai contoh kemasan produk yang baik disesuaikan dengan produk yang diproduksi oleh UMKM, dilanjutkan dengan diskusi untuk menganalisis beberapa kemasan produk pembanding. Metode evaluasi dengan mengamati hasil pelatihan yang didapat, yaitu peserta terlihat sangat antusias dan berdiskusi aktif untuk pengembangan kemasan produknya agar lebih bernilai jual.
\end{abstract}

Kata Kunci : Pelatihan, design kemasan, UMKM

\section{Pendahuluan}

Sektor Usaha Mikro, Kecil dan Menengah (UMKM) memberikan kontribusi yang besar dalam pembangunan ekonomi di Dunia dan Indonesia khususnya. Hal terbukti UMKM adalah usaha yang dapat bertahan dari krisis moneter yang melanda Indonesia di tahun 1999 dan 2008. Seiringan dengan Undang-Undang Otonomi Daerah, maka pemerintah daerah saling bersaing untuk menggali potensi daerahnya demi meningkatnya pendapatan asli daerah (PAD).

Tangerang Selatan sebagai kota pemerintahan yang berusia mudapun ikut serta berlomba dalam rangka peningkatan taraf hidup masyarakatnya. Terdapat lebih dari 26.700 UMKM yang ada di Tangerang Selatan, namun sangat disayangkan UMKM tersebut belum dapat mengembangkan potensi pasarnya dikarenakan keterbatasan pengetahuan dasar mengenai design kemasan. Desain kemasan ini merupakan hal penting karena tidak hanya menyangkut estetika tetapi juga keamanan dan ketahanan dari produk tersebut. Karena memeberikan nilai estetika, tentu saja keindahan design kemasan berguna untuk menarik minat, menjaga kualitas produk dan dapat menjadi daya saing dengan produk lain [6].

Kemasan seringkali disebut sebagai "key of product" karena mewakili kualitas dari produk dan jasa sendiri. Sehingga design kemasan harus sedemikian rupa agar mampu menyampaikan pesan dan kesan yang informatif dan menarik yang pada akhirnya sama persis bagaimana seperti halnya komunikasi antara penjual dengan pembeli. Para pakar pemasaran menyebut desain kemasan sebagai pesona produk (the product 
charm), sebab kemasan memang berada di tingkat akhir suatu proses alur produksi yang tidak saja untuk memikat mata (eye-cathing) tetapi juga untuk memikat pemakaian (usage attractiveness).[1][2]

Pada era industri 4.0 dimana sosial media dan media pemasaran sangat berkembang dan sedemikian informatif, kemasan mempunyai peranan yang sangat penting karena akan selalu terkait dengan komoditi yang dikemas dan sekaligus merupakan nilai jual dan citra produk. Nilai jual ini meningkat ketika produk yang dihasilkan mendapat nilai tambah dari kemasan yang menarik. Sedangkan citra produk terkait dengan gambaran produk dalam benak konsumen akan semakin baik apabila produk itu dikemas secara baik, dengan kata lain produk dapat memberi kesan baik bagi konsumen [7] [8].

Melihat permasalahan UMKM tersebut SoBiz-U LP2M ITI bersinergi dengan Dinas Koperasi dan UMKM Tangerang Selatan melaksanakan pelatihan Design kemasan kepada 100 undangan UMKM di Tangerang Selatan. Tujuan pelatihan ini adalah memberikan pelatihan demi peningkatan pengetahuan mengenai design kemasan untuk berbagai produk.

Sehingga kedepannya daya saing produk mereka dapat diterima dipasar global dan bertahan serta mengembangkan.

Berdasarkan gambaran di atas, maka permasalahan yang dihadapi oleh UMKM di Tangerang Selatan adalah sebagai berikut :

1. Design kemasan produk yang dihasilkan belum maksimal karena belum memiliki nilai estetika, ketahan dan keamana produk serta efisiensi dalam pengemasannya.

2. Era industri 4.0 memaksa para UMKM untuk melek teknologi karena tanpa adanya teknologi dalam pemasaran produk mereka, jika tidak dibarengi dengan kualitas yang baik (termasuk didalamnya adalah design kemasan) pasar mereka akan semakin menyempit akibat banyaknya pesaing diberbagai wilayah dengan produk UMKM sejenis, sehingga dibutuhkan ciri khas khusus sebagai added value dari produk UMKM Tangerang Selatan.

3. Semakin meningkatnya kebutuhan akan kemasan yang mampu meningkatkan penampilan serta nilai produk

\section{Metode Pengabdian}

Metode yang digunakan dalam pelaksanaan pengabdian adalah metode presentasi mengenai pengenalan bentuk dan desain packaging [6] Metode sharing session mengenai contoh kemasan produk yang baik disesuaikan dengan produk yang diproduksi oleh UMKM, dilanjutkan dengan diskusi untuk menganalisis beberapa kemasan produk dari berbagai industri makanan, minuman dan craft sebagai perbandingan.

Metode yang digunakan untuk peningkatan pengetahuan dan keterampilan sasaran adalah penyuluhan interaktif. Ada 3 tahap yang dilaksanakan pada kegiatan ini, yaitu:

1. Pra-Kegiatan Tahap pra-kegiatan dilakukan dengan cara: Survei kepada peserta pelatihan untuk mengetahui kemampuan dan kebutuhan

2. Pelaksanaan Kegiatan Pelaksanaan kegiatan dilakukan dalam bentuk diskusi dan sharing session tentang design kemasan dan label.

3. Evaluasi Hasil Kegiatan Evaluasi dilakukan dengan cara memberikan angket yang berisi pertanyaan/pernyataan tentang kemasan dan label makanan kepada peserta pelatihan. Jawaban dari pertanyaan tersebut adalah "ya" atau "tidak".

\section{Hasil Dan Pembahasan}

Sebelum kegiatan pelatihan dilakukan, terlebih dahulu diberikan penyampaian materi tentang kemasan dan label guna meningkatkan meningkatkan pengetahuan masyarakat. Penyampaian materi ini penting untuk dilakukan agar masyarakat dapat memahami dalam skala mikro dan kecil, misalnya dengan membuka usaha penjualan sembako, kue, dan lain-lain. Banyak juga di antara mereka yang memproduksi makanan ringan yang dijual di sekitar desa. Adapun hasil survei pra kegiatan terlihat pada Gambar 1, 2, dan 3 
1. Menurut tanggapan anda, apakah acara ini berjalan dengan baik dan lancar?

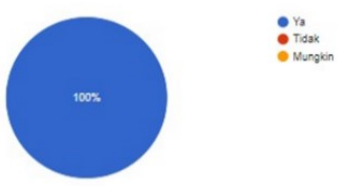

2. Apakah narasumber dapat menyampaikan materi dengan baik?
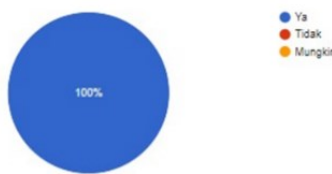

Gambar 1. Respon Survei Pra Kegiatan

3. Apakah materi tersebut dapat diahami?
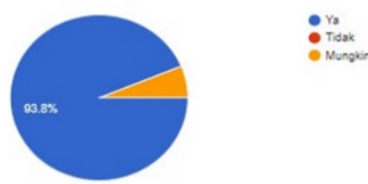

4. Apakah anda menyukai kegiatan ini?
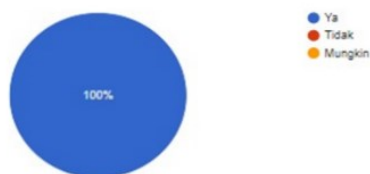

Gambar 2. Respon Survei Pra Kegiatan

5. Apakah setelah mengikuti pelatihan ini, anda termotivasi? 6responses

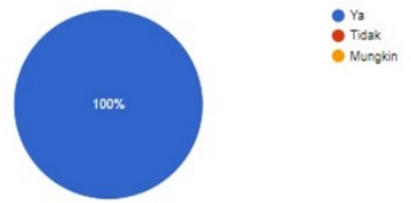

6. Untuk tahun ke depannya, apakah acara ini perlu diadakan lagi?
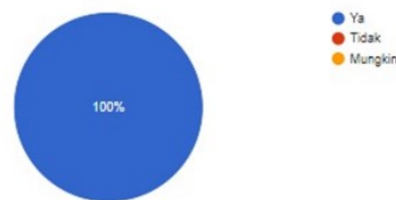

Gambar 3. Respon Survei Pra Kegiatan
Dari gambar 3. Respon Survei Pra Kegiatan diatas terlihat bahwa kebutuhan dan permintaan akan pelaihan design kemasan sangat penting bagi UMKM. Hal ini ditunjukan dari pertanyaan pada point ke 6 dimana $100 \%$ koresponden menginginkan pelatihan ini perlu dilakukan lagi dan memberikan dampak bertambahnya pengetahuan bagi para pelaku UMKM. Namun pada pelatihan ini belum dilakukan Analisa kebutuhan lebih mendalam dan da,mpak langsung maupun tidak langusng yang dirasakan oleh pelaku UMKM.

Berawal dari perminaan Dinas Koperasi dan UMKM Tangerang Selatan kepada SoBizU (Sekolah Bisnis UMKM) di Bawah LP2M ITI (Lembaga Pengabdian dan Pengembangan Masyarakat Institut Teknologi Indonesia) untuk bekerja sama dalam membantu meningkatkan kualitas produk UMKM Tangerang Selatan. . Kegiatan pengabdian kepada masyarakat dengan pokok materi pelatihan desain kemasan UMKM, dalam hal ini peserta diberikan bekal mulai dari pengenalan konsep pentingnya kemasan produk, kemasan standar untuk UMKM, kreatifitas desain kemasan untuk UMKM, labelling dan pengunaan barcode (code Batang),P- IRT, logo halal (komponen penting pada kemasan), branding/merk pada kemasan, dan trend kemasan saat ini. . [3][4][5] Pelaksanaan pengabdian ini dilakukan dalam bentuk penyuluhan, Tanya jawab, diskusi hingga penyelesaian kasus. Diharapkan dengan adanya pengabdian masyarakat ini UMKM mendapatkan wawasan dan pengetahuan tentang konsep pentingnya kemasan produk. UMKM mengetahui fungsi, kegunaan dan jenis kemasan yang dapat diterapkan pada produknya. Mampu merancang strategi kreatif desain kemasan dan perencanaan desain kemasan, serta mengetahui trend kemasan yang berlaku sekarang. Serta UMKM dapat merancang kemasan yang baik dan inovatif untuk produknya sehingga memberi nilai jual terhadap produk UMKM. 


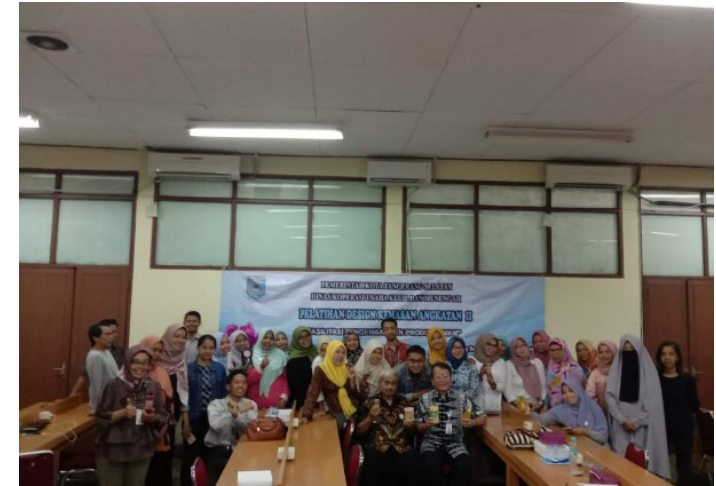

Gambar 4. Pelatihan Desain Kemasan

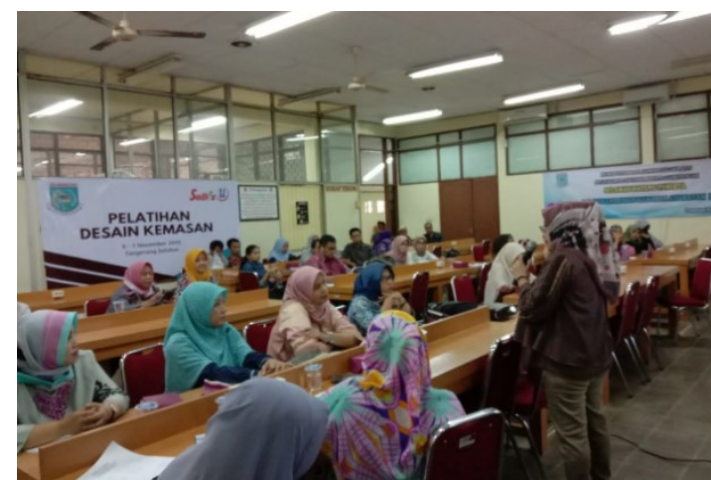

Gambar 5. Pemamaparan materi 1

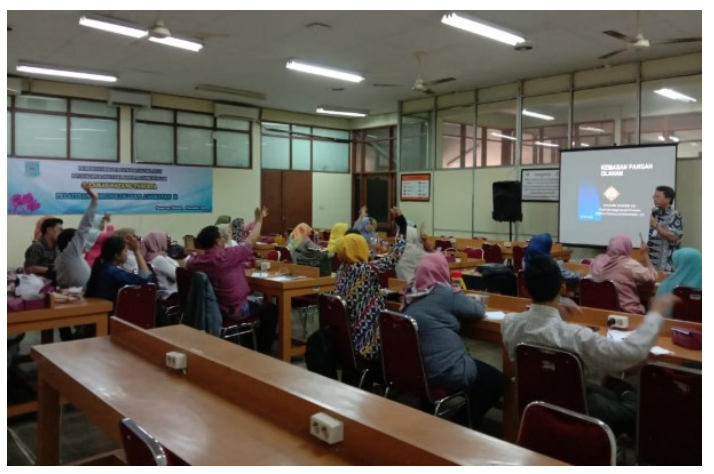

Gambar 6. Pemaparan materi 2

Hasil Evaluasi atas Intervensi Pelatihan Kemasan Untuk meyakinkan kemasan yang telah dibuat dapat menarik konsumen, dilakukan survey dengan menyebarkan kuesioner survei. Adapun hasil dari kuestioner tersebut adalah sebagai berikut :
1. Apakah peserta sudah pernah mengikuti pelatihan kemasan? 60 responses

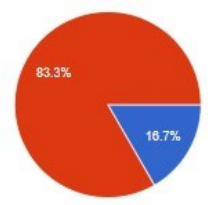

$$
\underset{\text { Tisak }}{\mathbf{v}_{\mathrm{s}}}
$$

2. Apakah peserta pelatihan membutuhkan pelatihan dengan tema kemasan atau tidak?

60 response

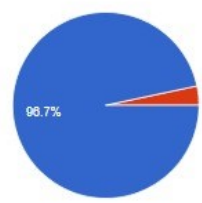

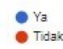

Gambar 7. Hasil Evaluasi Kegiatan

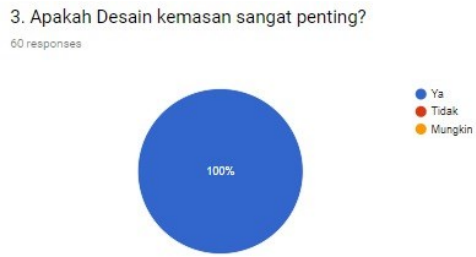

4. Apakah produk anda sudah memiliki desain kemasan?

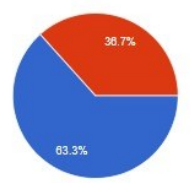

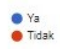

Gambar 8. Hasil Evaluasi Kegiatan

5. Apakah sudah memikirkan desain produk yang dapat menyampaikan informasi mengenai identitas bisnismu?

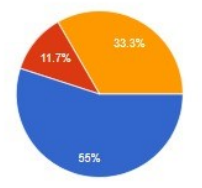

$$
\text { : Tidak }
$$

6. Apakah anda sudah mengetahui bagaimana cara membuat desain

kemasan produk yang bagus?

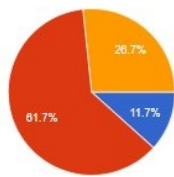

: Tidak

Gambar 9. Hasil Evaluasi Kegiatan 


\section{Kesimpulan}

Kegiatan pelatihan ini telah berlangsung dengan baik dan dapat meningkatkan pengetahuan sasaran dalam membuat label makanan yang baik dan memenuhi persyaratan. Materi yang disajikan dapat diterima, dicerna, dan dipahami peserta dengan baik. Kegiatan berlangsung lancar, tepat waktu dan sesuai dengan yang diharapkan dan para peserta dapat berkomunikasi dengan para pembicara dan peserta lain dengan baik.

\section{Ucapan Terimakasih}

Ucapan terima kasih disampaikan kepada pihak Direktorat Riset dan Pengabdian Masyarakat (DRPM) Direktorat Jendral Penguatan dan Pengembangan Kemenristek Dikti, Institut Teknologi Indonesia, Dinas Koperasi dan UMKM Tangerang Selatan yang mendanai kegiatan ini, dan mitra UMKM Tangerang Selatan yang turut andil dalam menyukseskan perlaksanaan program pengabdian kepada masyarakat melalui kegiatan Program Pengembangan Usaha Produk Intelektual Kampus (PPUPIK) tahun anggaran 2019.

\section{Daftar Pustaka}

[1] Aaron L. Bradly, Kenneth S. Marsh, The Wiley Encyclopedia of Packaging Technology, 2nd edition, A Wiley Interscience Publication, John Wiley \& Sons Inc., Canada, 1997

[2] Anonim, Indonesian Packaging Companies, Directory and Profiles 2002, PT. Carpricorn Indonesia Consult Inc., A Member of The CIC Consulting Group, Jakarta, 2002

[3] Coles R. Mc. Dowell D. Kirwan MJ. 2003. Packaging Tecnology. Boca Raton. CRC Press

[4] Klimchuk, Marianne Rosner \& Sandra A.Krasovec. (2007). Desain Kemasan Perencanaan Merek Produk yang Berhasil Mulai dari Konsep sampai Penjualan. Trans. Bob Sabran. Jakarta: Erlangga.

[5] Swann, Allan.1997. The New Graphic Design School. London: New Burlington Books.

[6] Wirya, Iwan. 1999. Kemasan Yang Menjual. Menang Bersaing Melalui Kemasan. Cetakan Pertama. Gramedia Pustaka Utama. Jakarta

[7] Gonzalez, M.P., Thorhsbury S., \& Twede D. 2007. Packaging as a tool for product development: Communicatingvalue to consumers. Journal of Food Distribution Research, 38 (1): 61-66.

[8] Resmi, N., dan Wismiarsi, T., 2015. Pengaruh Kemasan Dan Harga Pada Keputusan Pembelian Minuman Isotonik. Jurnal Manajemen dan Bisnis. Sriwijaya Vol.13 No.1 Maret 2015 